\title{
Thermal Patterns Created By Moisture Accumulation Within Exterior Masonry Walls
}

\author{
by A. Colantonio* and G. Desroches ** \\ * Public Works And Government Services Canada, Ottawa, Canada \\ ** Public Works And Government Services Canada, Edmonton, Canada
}

\begin{abstract}
In cold climates, air leakage is accompanied by moisture transport. When migrating through dew point temperatures, a considerable amount of moisture accumulation may occur depending on variables such as the duration of sub-zero exterior temperatures, building pressurization, wind effects and the level of interior relative humidity. Moisture accumulation may result in premature deterioration of wall assemblies and the formation of mould. When commissioning new building envelopes, or carrying out building condition inspections of existing building envelopes, it is imperative to differentiate the source of the moisture accumulation since the recommendation for remedial action will vary considerably. This paper will define the various types of thermal patterns created by surface penetration of water versus those patterns created by air leakage from the building interior in cold winter conditions. Various types of exterior masonry building envelopes will be discussed along with their hydrothermal performance characteristics and how these affect thermal patterns during various inspection procedures.
\end{abstract}

\section{Introduction}

In both extremely cold and hot humid climates, the control of water and water vapour through the building envelope is critical to the durability and long-term performance of the enclosure assemblies. In these climates, vapour retarders are used to control vapour diffusion.

Air barriers, either as single components or as a group of components are used to control air movement through the exterior through the exterior building envelope. Air movement can transport 10 to 100 times more moisture through unintentional openings in the air barrier assemblies than vapour diffusion through the leakiest vapour barrier or retarder. Detection of openings that facilitate moisture migration is critical to the control of vapour flow and moisture accumulation in exterior assemblies.

\section{Types Of Wall Assemblies}

Exterior wall assemblies can be designed as either a) face seal, or b) cavity wall. Within face seal assemblies there are both low mass or high mass type walls. Low mass walls consist of generally insulated stud walls (either load or non load bearing) with solar, wind, rain and vapour controlling exterior cladding. High Mass walls consist of solid masonry walls (either insulated or uninsulated). These high mass walls can either be loading bearing or enclose an integral steel or concrete structural frame. 
Face seal assemblies rely on one plane (mostly at exterior surfaces) for the purpose of stopping water, vapour and air migration into and though the wall. If and when there are breaches in these air and water vapour impermeable surfaces, the degree to which water can be evacuated is dependent on the drainage planes and permeability of the materials within the wall assembly and the cladding.1

The use of infrared thermography for detection of openings in air barrier assemblies can be carried out by means of pressurization of building interiors prior to infrared thermographic inspections. A resultant by-product of this type of inspection methodology in winter is the accumulation of moisture within the wall assemblies. Thermal patterns generated by building pressurization produce information on the location, type and possible severity of the air barrier opening. Prolonged building pressurization is accompanied by residual moisture accumulation in various building materials adjacent to air barrier breaches.

\section{Moisture Patterning As A Result Of Rainwater}

In cold climates, commissioning building envelope inspections are not always carried out in sub zero temperatures. Exterior ambient temperatures between $1^{\circ} \mathrm{C}$ and $10^{\circ} \mathrm{C}$ are conditions often experienced by thermographers testing buildings for air leakage faults. During these conditions rainfall may occur prior to actual inspections. The type of rainfall and intensity, along with wind conditions often result in variable wetting patterns on building claddings.

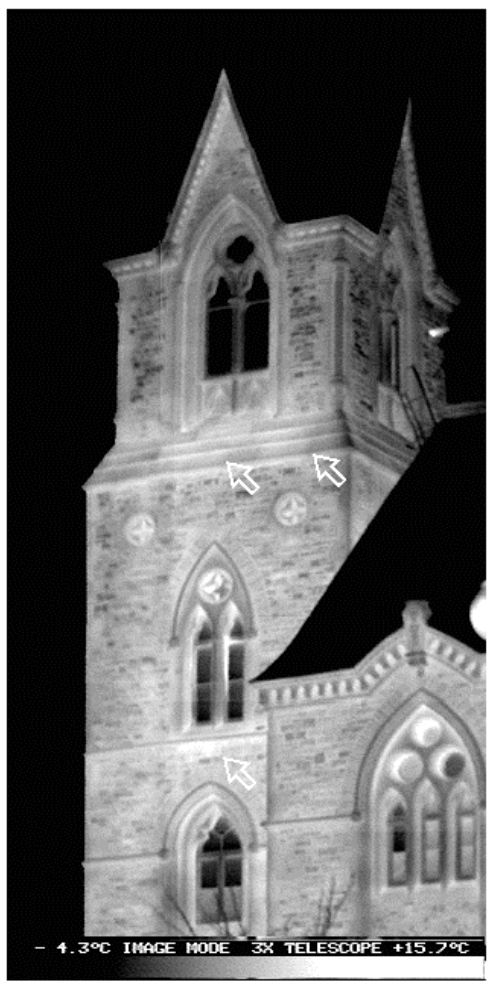

Both the type of cladding and assembly influences the variability of wetting patterns on walls. Non-porous cladding materials shed water and do not retain rainwater thus do not show variable effects of rainwater as surface temperatures after a rainfall. Porous materials show greater variable temperature effects as a result of moisture accumulation. Lightweight porous materials (wood and stucco) again show greater thermal variances due to rainwater penetration than high mass type porous material such as stone.

Rainwater patterns generally only affect cladding materials thus thermal patterns are a result of the reduced thermal resistance of the outer wall cladding materials.

Fig. 1.

Building Pressure; $0 \mathrm{~Pa}, \mathrm{~T}_{0}=-8^{\circ} \mathrm{C}$, No precipitation or snowfall for at least 7 days prior to inspection. Arrows point to suspected moisture accumulation within the limestone cladding due to rain and melt water throughout winter months. 
In cold climates the most significant durability issue is the potential for freeze thaw damage to the cladding materials at areas where saturation occurs. In locations where rainwater penetration gets through the cladding, other materials such as weather barriers and sheathing often protect entry into the insulation layers and structure. In some conditions, where penetration does occur into these materials, infrared thermography is able to locate these problem areas when temperature gradients greater than $10^{\circ} \mathrm{C}$ exist through the building exterior envelope.

Rainwater penetration patterns are generally associated with the top section of walls and most likely around parapet walls. Unless buildings are located in areas with a high driving rain index, most building only experience rainwater penetration along the top floors. Other areas where rainwater penetration may occur are at sloped or protruding walls or drainage planes from upper wall sections. Windowsills and parapets are examples of such drainage features. Sloped relief details in stone masonry walls are another example of such conditions. (Refer to Fig. 1)

\section{Moisture Patterning As A Result of Melt Water}

In winter months, solar gain and thaw conditions result in melt water runoff from roofs, sloped projections and other architectural features. In these situations, masonry and other porous cladding materials are affected by the accumulation of surface moisture. These patterns are visible through infrared thermography as a result of the temperature differential between interior and exterior.

Melt water patterns are affected by solar heat gain and often dry out on the surface but interstitial moisture remains throughout the winter months. Moisture accumulation due to melt water may often not be visible due to surface drying aided by solar heat gain but subsurface cladding moisture is detectable through the use of infrared thermography. The significance of this moisture is that it can result in increased freeze thaw potential in the mortar and premature rusting of metal within the masonry.

Sloped areas on stone and masonry walls are areas that attract melt water throughout the winter months. Often these areas are characterized by staining and dirt build up created by surface water accumulation. In many of our building investigated there was a correlation between the dirt build up on stones and moisture accumulation within the wall and specific stones.

\section{Moisture Patterning As A Result of Ground Water}

Solid masonry walls with stone foundations (without ground protection) are susceptible to ground water absorption through capillarity at the first floor of the building. Reduced thermal resistance values occur at the stone walls immediately above the ground. During the heating season, this moisture may result in mortar deterioration at the outer section of the wall due to freeze thaw. Infrared inspection of these walls can detect moisture accumulation by means of increased surface temperatures. Thermal patterns are not mottled as in other types of assemblies but rather consistently warmer throughout the lower sections of the first floor adjacent to the grade and ground soil. 
In general surface temperature variations between the first floor walls and the rest of the building can only be discerned at exterior ambient temperatures below -5 to $-10^{\circ} \mathrm{C}$. Inspections carried out during higher temperatures require more sensitive infrared equipment to discern rising damp surface temperature variations.

\section{Negative Air Leakage Testing and Exterior Ambient Temperatures}

The two images below (Fig. 2 \& 3) demonstrate the amount of moisture accumulation that can occur within masonry cladding as a result of stack effect brought on by winter exterior ambient temperatures. Both images taken during negative building pressures are void of air exfiltration patterns but Fig. 3, taken at a lower ambient temperature $\left(-11^{\circ} \mathrm{C}\right)$, displays greater amount of moisture accumulation within the masonry cladding at the top of the building than Fig. 2 taken at temperatures approximately $11^{\circ} \mathrm{C}$ higher.

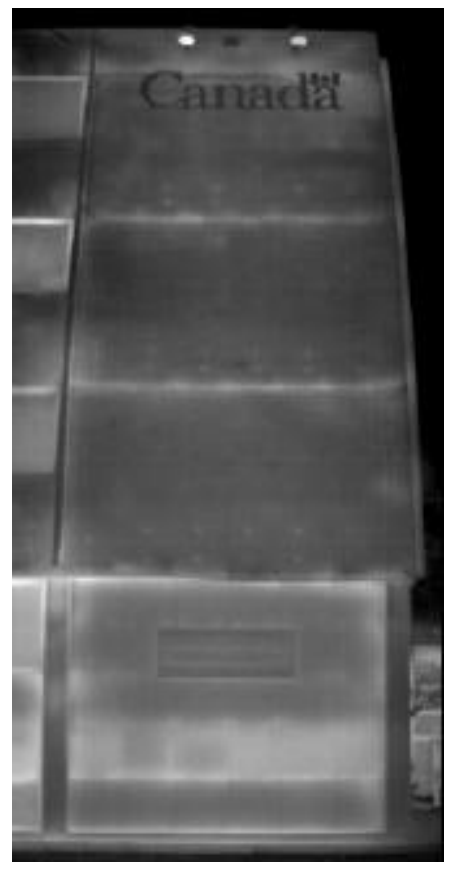

Fig. 2.

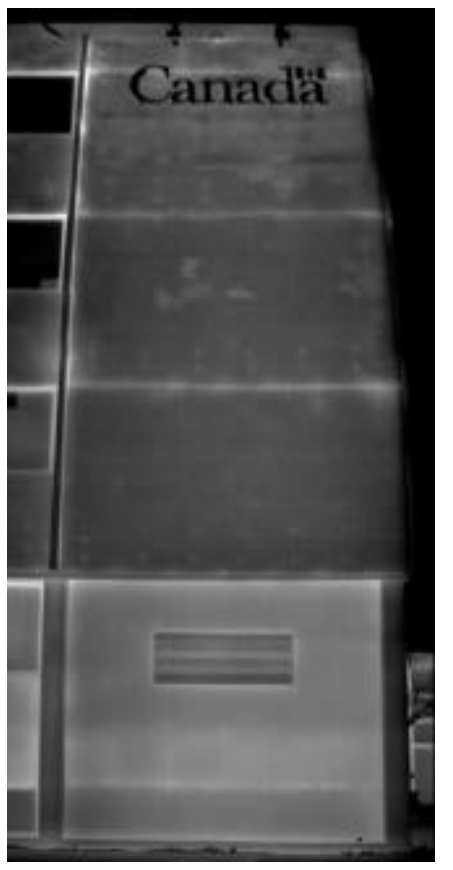

Fig. 3.

Building Pressure $(-140 \mathrm{~Pa}), T_{0}=0^{\circ} \mathrm{C} \quad$ Building Pressure $(-8 \mathrm{~Pa}), T_{0}=-11^{\circ} \mathrm{C}$

The only other variable in Fig. 2 is significantly increased negative pressure in the higher temperature situation that could have resulted in modification of existing moisture patterns. The increased negative pressure combined with the time prior to inspections may have reduced the amount of moisture within the wall cladding. In addition, due to reduced exterior ambient temperatures, stack effect would have been reduced for the period prior to capture of image in Fig. 2, thus reducing the amount of moisture especially at the top of the building envelope. 


\section{Positive Air Leakage Testing And Exterior Ambient Temperatures}

Fig. 4 \& 5 demonstrate the amount of moisture accumulation that can occur within masonry cladding as a result of stack effect brought on by reduced exterior ambient temperatures. Both images, taken during positive building pressures, display thermal patterns created by air exfiltration in addition to previously accumulated moisture patterns due to stack effect pressures. Air leakage patterns appear warmer thus overpower moisture induced thermal patterns in both exterior ambient temperature conditions.

Fig. 5. taken at temperatures of approximately $11^{\circ} \mathrm{C}$ lower than Fig. 4 illustrates greater amount of moisture accumulation within the masonry cladding at the top floor. This is consistent with thermal patterns produced during the negative building pressure inspections. The other variable in these images is the slightly increased positive pressure in the higher temperature situation (Fig. 4) that could have resulted in the slight modification of existing moisture patterns.

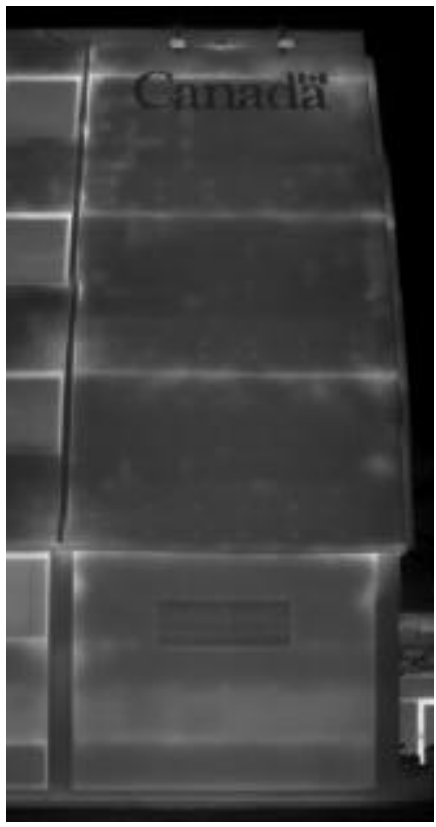

Fig. 4.

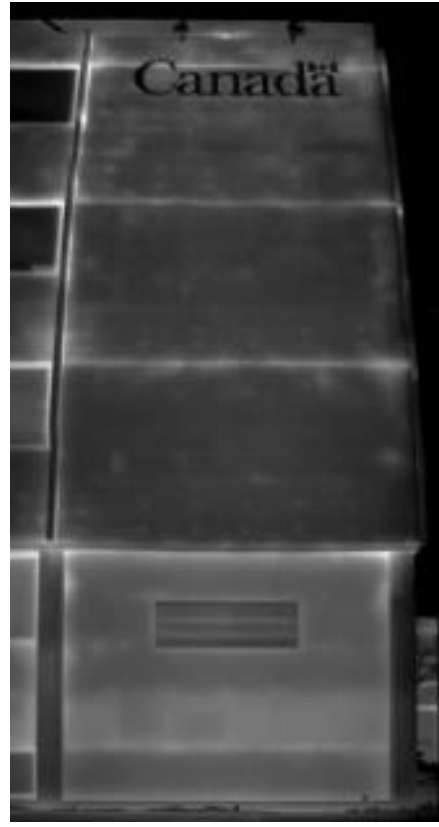

Fig. 5.

Building Pressure $(+40 \mathrm{~Pa}), T_{0}=0^{\circ} \mathrm{C} \quad$ Building Pressure $(+25 \mathrm{~Pa}), T_{0}=-11^{\circ} \mathrm{C}$

\section{Direct And Diffuse Air Leakage And Resultant Moisture Patterning}

The thermal images seen in Fig. 6 to 9 demonstrate the variances between moisture patterns created by both direct and diffuse air leakage. These images also illustrate the variations during both positive and negative pressure conditions during inspections. 
Moisture patterning is most visible during negative building pressure inspections since air leakage patterns do not overpower those created by moisture within the cladding or insulation. Moisture patterning created by normal operating conditions are more visible in the infrared when conducting inspections within an hour or so after initializing negative building pressure. Moisture patterning appears to be more apparent in areas where diffuse air leakage occurs through the exterior walls rather than at areas where direct air leakage occurs during these inspections. One possible explanation for this phenomenon is that in diffuse air leakage conditions, moisture has a greater potential to get trapped into porous materials rather than in situations where direct air leakage occurs.

What has been generally observed is that moisture accumulation around areas of direct airflow paths occurs at the peripheral areas of the openings and not at their immediate locations. Again heat and air flow from the exfiltrating air generally will not allow for moisture retention at the immediate opening but rather some distance around the openings where there is less air flow to move the moisture further out of the cladding material. In very cold conditions $\left(-30^{\circ} \mathrm{C}\right.$ and lower $)$, visual signs of hoar frosting is visible peripherally around the problem area.

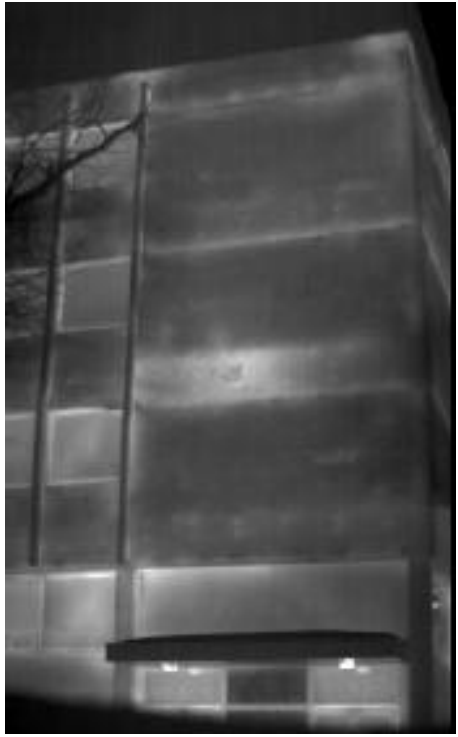

Fig. 6.

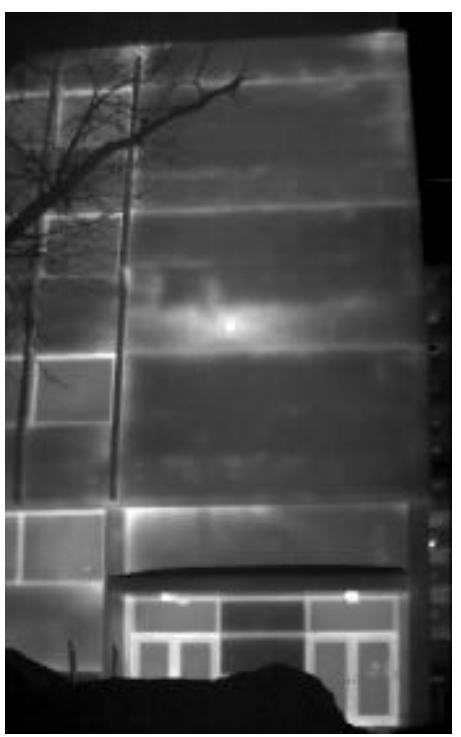

Fig. 7.

Building Pressure (-140 Pa), $T_{0}=0^{\circ} \mathrm{C} \quad$ Building Pressure $(+40 \mathrm{~Pa}), T_{0}=-0^{\circ} \mathrm{C}$

Pre-existing moisture patterning does not seem to be affected to any degree during positive pressure inspections other than to make them less apparent due to the warmer surface temperatures created by exfiltrating air. Positive building pressure inspections will result in additional moisture deposition within the wall assembly and thus create additional areas of moisture accumulation within the wall area that may not be present during normal operating conditions of the building. Both, significant building pressure (between 50 to $150 \mathrm{~Pa}$ ) and considerable duration 
(greater than 4 hours of positive pressure) are required before additional moisture patterning is visible due to positive building pressure conditions in buildings.

When looking at buildings during cold weather conditions, variations in the thermal signatures created by naturally occurring weather conditions will take considerable time to be modified and in some conditions, may not be modified at all. In Fig. 6 to 9 the masonry areas around the vent located in the central section of the third floor appears warm even in the negative pressure inspections even through negative pressures were imposed more than 2 hours prior to each inspection. Exterior ambient temperature seems to have little affect on the dissipation of stored heat and moisture within the masonry around these areas. Greater time is required under negative building pressure to eliminate the stored heat from air leakage within the masonry cladding due to intentional and unintentional wall openings.

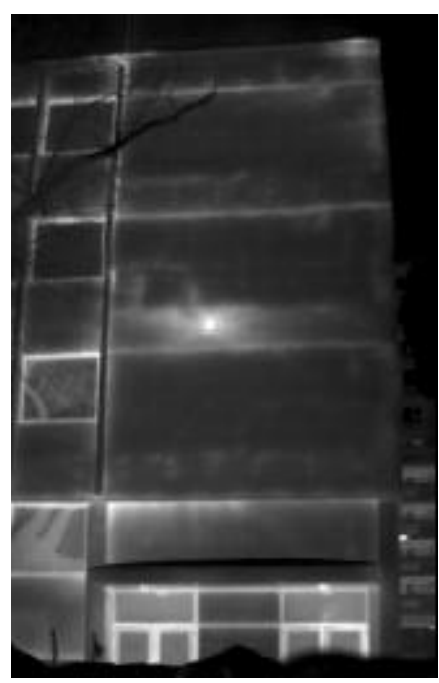

Fig. 8.

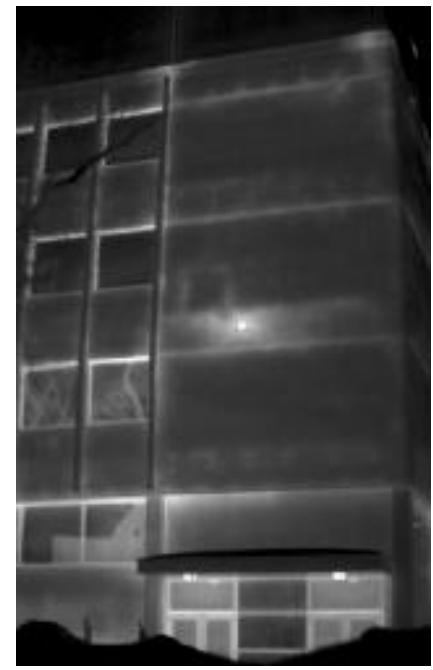

Fig. 9.

Building Pressure $(-140 \mathrm{~Pa}), T_{0}=-11^{\circ} \mathrm{C} \quad$ Building Pressure $(+40 \mathrm{~Pa}), T_{0}=-11^{\circ} \mathrm{C}$

\section{Duration of High Building Pressure And Moisture Accumulation}

The composite thermal images in Fig. 10 \& 11 were taken on subsequent mornings. The positive pressure imagery (Fig. 11) was produced 24 hours prior to the negative pressure imagery in Fig. 10. The arrows at the parapet walls of this 24storey building identify the moisture accumulation within the brick cladding as a direct result of positive building pressure imposed on the building for air leakage testing. These moisture patterns were not present prior to the positive building pressure being induced into the building and did not appear until after 4 hours of positive building pressure. 


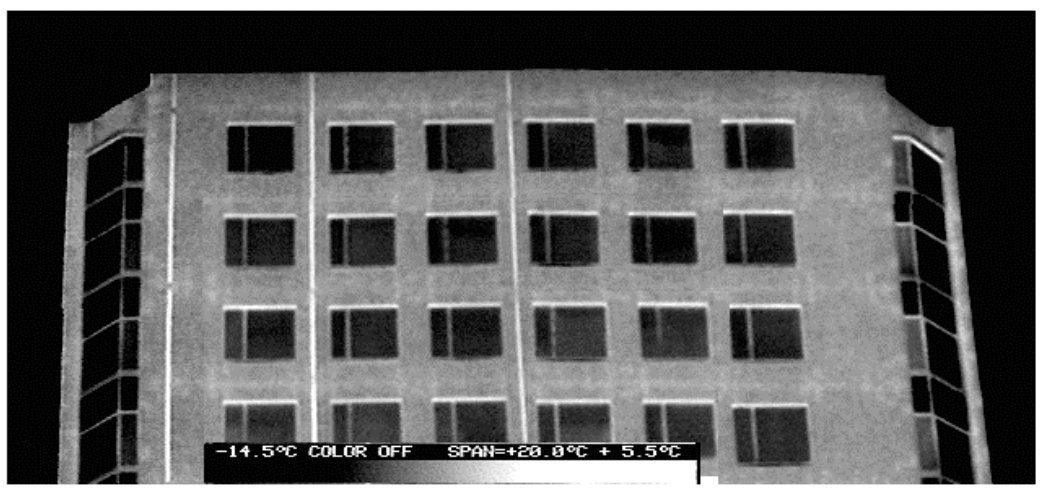

Fig. 10

Negative Building Pressure (-60 Pa), $T_{o}=-7^{\circ} \mathrm{C}$, maintained for a duration of 4 hours prior to inspection.

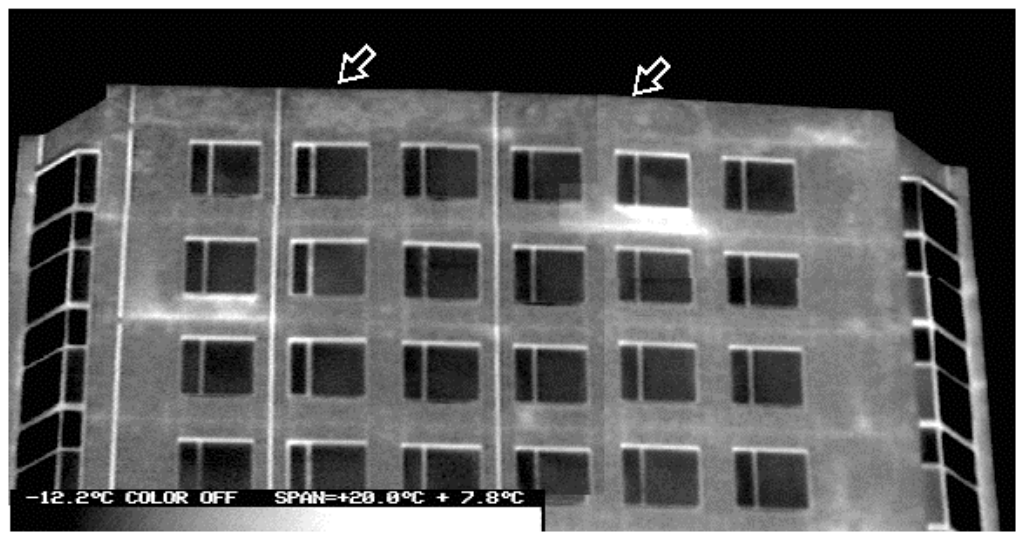

Fig. 11

Positive Building Pressure (80 Pa), $T_{o}=-7^{\circ} \mathrm{C}$, maintained for a duration of 5 hours prior to inspection.

In Fig. 11, leakage areas were random in various sections of the building and not widespread, but the sustained abnormal positive building pressure during testing did result in additional moisture migration from the building into the masonry cladding. This is a common occurrence in both solid as well as cavity wall assemblies. In cavity wall assemblies, moisture migration often travels from the source of the air barrier opening, up to the top sections of the wall cavity due to convection. Another factor that contributes to the increased build-up of moisture accumulation at top sections of buildings is the increased stack effect pressures generally found at these elevations during winter months and the lack of through wall heat flow at parapet walls.

Fig. 10 illustrated the thermal imagery from the same area of this building while being subjected to negative building pressure the following evening. Thermal patterns due to air leakage are absent as are patterns created by moisture accumulation within the brick cladding at the parapet walls 


\section{Exterior Ambient Temperatures And Phase Change Of Moisture}

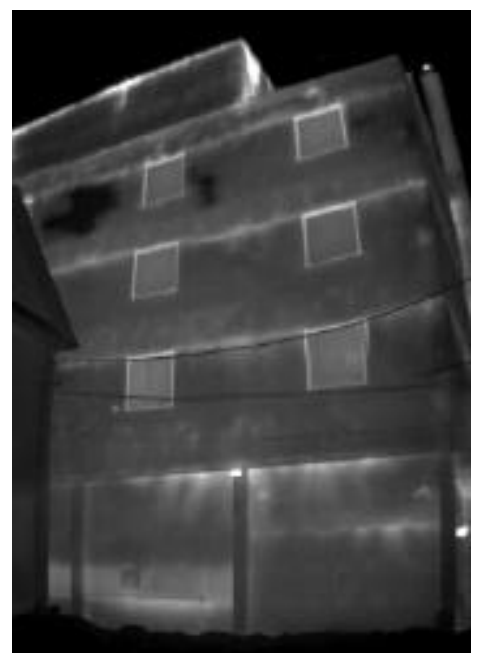

Fig. 12

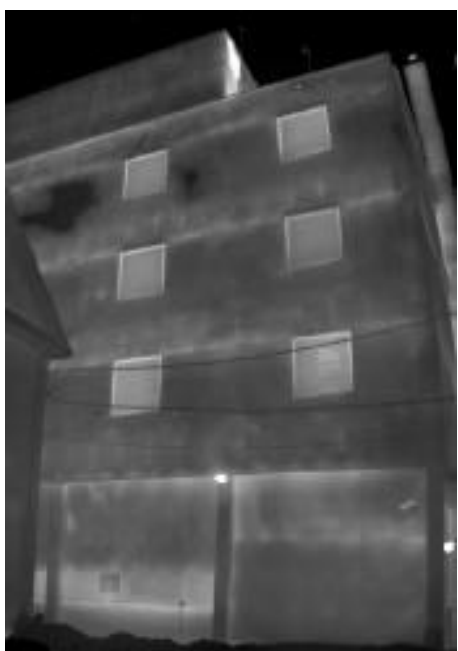

Fig. 13

Building Pressure $(+40 \mathrm{~Pa}), T_{o}=0^{\circ} \mathrm{C}$, Building Pressure $(-140 \mathrm{~Pa}), T_{o}=0^{\circ} \mathrm{C}$ Both images taken during same evening, 4-hour time span between the two images.

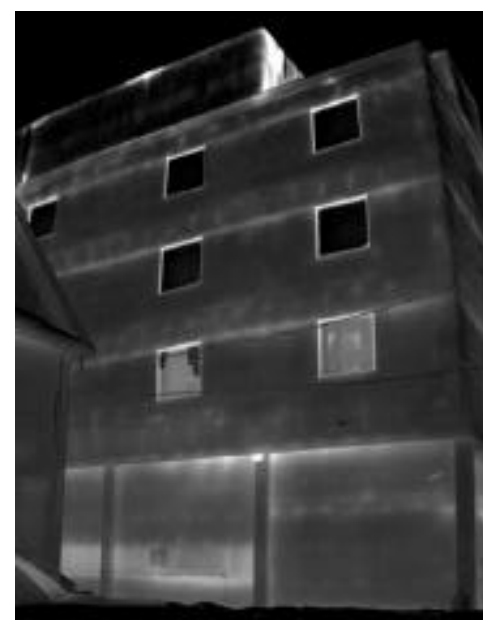

Fig. 14

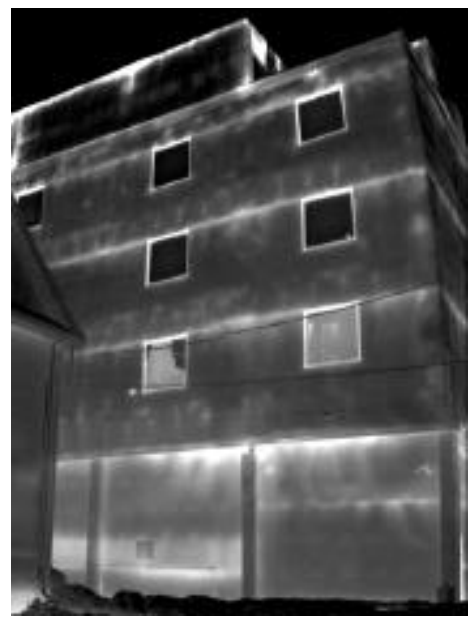

Fig. 15

Building Pressure (-8 Pa), $T_{o}=-11^{\circ} \mathrm{C}$ Building Pressure $(+25 \mathrm{~Pa}), T_{o}=-11^{\circ} \mathrm{C}$ Both images taken during same evening, 4-hour time span between the two images.

Phase change of moisture within porous cladding materials occurs at temperatures at or slightly below freezing. In these conditions frozen surface 
moisture is visible through reduced surface temperatures as the frozen surface moisture freezes and thaws. This phenomenon occurs independent of either positive or negative pressures. Fig. 12 to 15 illustrate this point.

The dark areas on the $4^{\text {th }}$ floor masonry illustrate the thermal pattern generated by the phase change of masonry moisture. It appears reasonably consistent during both the negative and positive inspections during the same evening where freezing occurred.

Fig. 14 \& 15 were taken during same evening with significantly sub zero outdoor ambient temperatures, 4 hours between the two settings. Due to the lower exterior ambient temperatures, phase change phenomenon is not visible. Moisture accumulation is visible during both inspections, but easier to detect and determine from air leakage patterning during negative pressure conditions than positive pressure conditions.

\section{Summary}

Moisture patterns within masonry cladding created by air leakage from interior sources due to stack effect are most prominent at upper sections of building during sub zero winter months. These patterns are more visible immediately after negative building pressure conditions have been induced rather than positive building pressure conditions. In situations where normally occurring exfiltration results in localized increased cladding temperatures and resultant moisture accumulation, a time duration of greater than 24 hours is needed to eliminate the effect of that normal heat loss pattern.

When positive building pressure inspections are carried out in sub zero ambient conditions, there is risk that building interior water vapour driven into porous cladding materials will condense. When these conditions are maintained for greater than 4 hours, moisture accumulation is visible on masonry cladding. If positive building pressure conditions are not normal, then this resultant moisture accumulation dissipates over a 24 hour time period. When conducting exterior large building infrared thermographic inspections during cold winter months, it is advised to conduct the negative building pressure inspection prior to the positive building inspection IF both are planned for one evenings work. If the work is spread out over a number of days, then either inspection can be carried out first since the resultant moisture accumulation from internal sources will be allowed to dissipate.

Phase change of moisture within porous cladding materials is visible only during exterior ambient temperature conditions between $0^{\circ} \mathrm{C}$ and $-3^{\circ} \mathrm{C}$ when moisture within the cladding is most susceptible to phase change. Positive and negative building pressure conditions do not affect the formation and detection of moisture within the process of phase change.

\section{REFERENCES}

[1] A. Colantonio, and G. Desroches. Thermal patterns on solid masonry and cavity walls as a result of positive and negative building pressures, Proc. Thermosense XXVII; SPIE Vol. 5782, March 2005, pp 176 - 187. 